\title{
The diagnosis of Legionnaires' disease by counterimmunoelectrophoresis
}

\author{
MALCOLM G HOLLIDAY \\ From the Microbiology Department, St George's Hospital, Stafford, UK
}

SUMMARY Counterimmunoelectrophoresis (CIE) was found to be a rapid, specific method for detecting circulating antibodies to Legionella pneumophila, the aetiologic agent of Legionnaires' disease in human sera. Optimum conditions for performing the test are given. Better precipitin lines are observed when the gel support is neutral, and a result may be obtained in 90 to 180 minutes. Comparison of results of CIE and indirect fluorescent antibody tests on 22 sera from patients with Legionnaires' disease and on 27 sera from healthy control subjects showed $100 \%$ correlation, and 75 paired sera from patients with pneumonia of unknown aetiology showed $96.7 \%$ correlation. Laboratory diagnosis may be made quickly and accurately by CIE. The method is simple and easily performed in the routine laboratory. The antigen is stable at $4{ }^{\circ} \mathrm{C}$ for at least six months.

The term Legionnaires' disease is currently used to refer to illness resulting from infection with the bacterium that caused the 1976 outbreak in Philadelphia or from infection with another strain of the same organism. ${ }^{12}$ This organism has now been named Legionella pneumophila. ${ }^{3}$

L. pneumophila is a fastidious, Gram-negative bacillus, the culture of which is difficult, ${ }^{14}$ and the demonstration of which in tissues requires special stains. ${ }^{5}$ Direct methods do not detect this disease efficiently, ${ }^{4}$ and so diagnosis is usually dependent on serological evidence. ${ }^{5}$ To date, the most widely used diagnostic technique in the United Kingdom is the indirect fluorescent antibody test (IFA). ${ }^{6}$ However, several problems exist with this method. ${ }^{7-9}$ Diagnostic reagents for IFA are available in the United Kingdom (Division of Microbiological Reagents and Quality Control, Colindale (DMRQC)); any serological diagnosis, however, should be confirmed by one of the Legionnaires' disease reference centres. ${ }^{10}$

The purpose of the present investigation was to evaluate a counterimmunoelectrophoresis (CIE) method for the diagnosis of Legionnaires' disease and to compare the results with those obtained by IFA. The application of this technique to the diagnosis of Legionnaires' disease was suggested by the speed and economy afforded in handling large numbers of sera for screening and by the permanent

Received for publication 10 June 1980 stained records that can be made, a feature not possible with IFA except by photography.

\section{Material and methods}

ANTIGEN PREPARATION

Heat-killed cells of the Philadelphia 1 strain of serogroup $1 \mathrm{~L}$. pneumophila were kindly supplied by Dr AG Taylor, Colindale, London. The organisms were grown on Oxoid No. 2 blood agar, plus Lcysteine hydrochloride $(0.4 \mathrm{~g} / \mathrm{l})$ and ferric pyrophosphate $(0.25 \mathrm{~g} / \mathrm{l})$ with $7 \%$ defibrinated horse blood $^{11}$ at $37^{\circ} \mathrm{C}$ for 72 hours. The growth from two plates was added to approximately $10 \mathrm{ml}$ of Dulbecco A phosphate buffered saline (PBS) and heated at $100 \mathrm{C}$ for 15 minutes. ${ }^{10}$

When received, the density of the organisms was approximately equal to an opacity tube made up as follows: $92 \mathrm{ml} 1 \%$ sulphuric acid plus $8 \mathrm{ml} 1 \%$ barium chloride solution.

The organisms were then disrupted in a Rapidis A 180G Ultrasonic Disintegrator for 20 minutes, disintegration being monitored by Gram's stain using dilute carbol fuchsin as counterstain. Cooling was provided by an ice bath. The resulting cloudy fluid was used neat as the antigen. Sodium azide was added to a final concentration of $0 \cdot 1 \%$.

S E R A

Twenty-two sera from confirmed Legionnaires' disease patients and 75 paired sera from pneumonia 
patients sent for Legionnaires' disease serology were made available, and 27 control sera were obtained from healthy members of the hospital staff.

\section{COUNTERIMMUNOELECTROPHORESIS}

CIE was performed on $2.5 \times 7.5 \mathrm{~mm}$ glass microscope slides coated with $3 \mathrm{ml} 1 \%$ Agarose (BDH) in barbitone acetate buffer $\mathrm{pH} 7 \cdot 0$, ionic strength $(\mu)=0 \cdot 1$. (This was made up as follows: $13.38 \mathrm{~g}$ sodium barbitone and $8.83 \mathrm{~g}$ sodium acetate trihydrate in 1.51 distilled water. $0.1 \mathrm{~N} \mathrm{HCl}$ was used to adjust the $\mathrm{pH}$ to the required level.) The slides were stored at $4^{\circ} \mathrm{C}$ overnight in a moist atmosphere before use to allow the gel structure to stabilise. Barbitone acetate buffer $\mathrm{pH} 8.6 \mu=0 \cdot 1$, was employed in the buffer chambers. Wells $3 \mathrm{~mm}$ in diameter and $2 \mathrm{~mm}$ apart were cut in the agar. $12 \mu \mathrm{l}$ serum was placed in the anode wells and $12 \mu \mathrm{l}$ antigen in the cathode wells using a SMI microsyringe. Electrophoresis was performed at room temperature using a constant current of $10 \mathrm{~mA}$ per slide for 90 minutes. After this the slides were incubated in a moist chamber at $4{ }^{\circ} \mathrm{C}$ for 30 minutes, washed in alkaline phosphate buffer (sodium phosphate $\mathbf{0} \cdot 2 \mathrm{M}, \mathrm{pH} 8 \cdot 6$, containing $0.4 \%$ sodium citrate) for 30 minutes and examined.

The slides were then washed overnight in physiological saline at room temperature, dried between filter paper sheets, and stained with $0.5 \%$ naphthalene black in methanol:acetic acid:water buffer $(5: 1: 4)$. Decolorisation was in the same buffer.

All electrophoresis used Cambrelle (ICI Ltd) as wick material, Shandon Southern electrophoresis baths, and Vokam powerpacks.

\section{Results}

The type of gel support was found to affect the results of CIE tests for Legionnaires' disease in a variety of ways, as shown in Table 1. Optimal results were obtained with $1 \%$ agarose in barbitone acetate buffer between pH 6.6 and 7.0 and ionic strength $\mu=0 \cdot 1$. The neutral $\mathrm{pH}$ was chosen eventually because at $\mathrm{pH} 6.6$ the gel tended to crystallise slightly on storage at $4{ }^{\circ} \mathrm{C}$, but there were no qualitative differences in the results observed between the two pHs. Almost central presipitin lines were seen, and maximum clarity was achieved with this system. Positive reactions developed with electrophoresis for 90 minutes at $10 \mathrm{~mA}$ per slide. Increasing the current or length of electrophoresis caused no appreciable improvement in results.

When slides were examined immediately after electrophoresis, non-specific precipitation, seen as wide diffuse arcs around the serum wells, was noted. After incubation at $4^{\circ} \mathrm{C}$ to develop further the specific precipitation reactions, the non-specific precipitation was quite marked and made visualisation of test results difficult. However, after the slides had been washed in alkaline phosphate buffer non-specific reactions completely disappeared and only specific reactions were left.

Table 2 summarises the results of CIE and IFA

Table 1 Effect of gel support on CIE for detection of artibody to Legionella pneumophila

\begin{tabular}{|c|c|c|c|c|c|c|}
\hline \multirow[t]{2}{*}{ Gel support } & \multirow[t]{2}{*}{$p H$} & \multirow{2}{*}{$\begin{array}{l}\text { Ionic } \\
\text { strength } \\
(\mu)\end{array}$} & \multicolumn{3}{|c|}{ Precipitin lines } & \multirow{2}{*}{$\begin{array}{l}\text { Crystallisation } \\
\text { at } 4^{\circ} \mathrm{C}\end{array}$} \\
\hline & & & Site* & Shape $†$ & Intensity $\ddagger$ & \\
\hline \multirow[t]{17}{*}{$1 \%$ agarose in barbitone acetate buffer } & \multirow[t]{2}{*}{$6 \cdot 3$} & 0.1 & $\mathrm{CL} / \mathrm{Ag}$ & C & G & + \\
\hline & & 0.05 & CL/Ag & C & $\mathbf{M}$ & + \\
\hline & \multirow[t]{2}{*}{$6 \cdot 6$} & $0 \cdot 1$ & $\mathrm{CL}$ & $\mathbf{S}$ & G & \pm \\
\hline & & 0.05 & CL & $\mathbf{S}$ & $\mathbf{M}$ & \pm \\
\hline & \multirow[t]{2}{*}{$7 \cdot 0$} & $0 \cdot 1$ & $\overline{C L}$ & $\mathbf{S}$ & G & - \\
\hline & & 0.05 & CL & $\mathbf{S}$ & $\mathbf{M}$ & - \\
\hline & \multirow[t]{2}{*}{$7 \cdot 5$} & $0 \cdot 1$ & $\mathbf{A b}$ & $\mathrm{S} / \mathrm{C}$ & G & - \\
\hline & & 0.05 & $A \mathbf{b}$ & $\mathrm{S} / \mathrm{C}$ & W & - \\
\hline & \multirow[t]{2}{*}{$8 \cdot 0$} & $0 \cdot 1$ & $\mathbf{A b}$ & $\mathrm{C}$ & $\mathbf{M}$ & - \\
\hline & & 0.05 & $\mathbf{A b}$ & C & W & - \\
\hline & \multirow[t]{2}{*}{$8 \cdot 2$} & $0 \cdot 1$ & $\mathrm{Ab}$ & C & $\mathbf{M}$ & - \\
\hline & & 0.05 & $\mathrm{Ab}$ & C & $\mathbf{W}$ & - \\
\hline & \multirow[t]{3}{*}{$8 \cdot 6$} & $0 \cdot 1$ & $\mathrm{Ab}$ & C & $\mathbf{W}$ & - \\
\hline & & 0.05 & $\mathbf{A b}$ & C & W & - \\
\hline & & 0.02 & $\mathrm{Ab}$ & C & VW & - \\
\hline & \multirow[t]{2}{*}{$9 \cdot 0$} & $0 \cdot 1$ & $\mathrm{Ab}$ & C & $\mathbf{W}$ & - \\
\hline & & 0.05 & $\mathbf{A b}$ & C & VW & - \\
\hline \multirow{4}{*}{$\begin{array}{l}1 \% \text { agarose in Tris buffer } \\
1 \% \text { agarose in Tris, EDTA, borate buffer } \\
1 \% \text { agarose in sodium borate buffer } \\
0.75 \% \text { agarose plus } 0.75 \% \text { plain agar } \\
\text { in barbitone acetate buffer }\end{array}$} & $8 \cdot 2$ & $0 \cdot 1$ & $\mathrm{Ag}$ & C & $\mathbf{M}$ & - \\
\hline & $+7 \cdot 0$ & $0 \cdot 1$ & Ag & C & VW & - \\
\hline & $8 \cdot 6$ & $0 \cdot 1$ & $\mathbf{A b}$ & C & VW & - \\
\hline & $8 \cdot 6$ & $0 \cdot 1$ & $A b$ & $\mathbf{S}$ & VW & - \\
\hline
\end{tabular}

*CL = central, $\mathrm{Ab}=$ close to antibody well, $\mathrm{Ag}$ close to antigen well

$+\mathrm{C}=$ curved, $\mathrm{S}=$ straight

$\ddagger \mathbf{G}=$ good, $\mathbf{M}=$ moderate, $\mathbf{W}=$ weak, $V W=$ very weak. 
Table 2 Comparison of IFA and CIE tests on sera from Legionnaires' disease patients, healthy controls, and non Legionnaires' disease pneumonia patients

\begin{tabular}{lccc}
\hline Patient group & Totalsera & $\begin{array}{l}\text { CIE }+v e \\
(\% \text { of total })\end{array}$ & $\begin{array}{l}\text { CIE - ve } \\
(\% \text { of total })\end{array}$ \\
\hline $\begin{array}{l}\text { LD sera } \\
\text { IFA } \geqslant 32\end{array}$ & 17 & $17(100)$ & 0 \\
$\begin{array}{l}\text { LD sera } \\
\text { IFA }<32\end{array}$ & 5 & 0 & $5(100)$ \\
$\begin{array}{l}\text { Control sera } \\
\text { IFA < 16 }\end{array}$ & 27 & 0 & $27(100)$ \\
$\begin{array}{l}\text { Pneumonia sera } \\
\text { IFA < } 16\end{array}$ & 150 & $5(3 \cdot 3)$ & $145(96 \cdot 7)$ \\
\hline
\end{tabular}

tests on the control sera, the pneumonia sera, and the Legionnaires' disease patients sera. All sera from Legionnaires' disease patients with IFA titres $\geqslant 32$ were positive by CIE, and all sera from these patients with IFA titres $<32$ were negative by CIE. All the normal control sera were CIE negative, and $96.7 \%$ of the non Legionnaires' disease pneumonia sera were CIE negative. The remaining $3.3 \%$ of these were positive by CIE neat, but negative at a dilution of $1 / 2$.

Table 3 shows the relation between IFA and CIE titres obtained with sera from the Legionnaires' disease patients. Serial specimens become CIE positive when the IFA titre reaches $32-64$. As the time from onset progresses there appears to be a roughly linear relation between IFA and CIE titres, best exemplified in patient 5 . This is not true of all patients, however.
The earliest positive reaction detected by CIE was 10 days after onset (patient 6). Serum from patient 10 obtained 182 days after onset was still positive at a high titre by CIE.

When rabbit hyperimmune antiserum to $L$. pneumophila serogroup 1 was tested by CIE, a titre of $1 / 16$ was obtained. When rabbit hyperimmune antisera to $L$. pneumophila serogroups 2,3 , and 4 were similarly tested, there were no reactions.

Antigen stored at $4^{\circ} \mathrm{C}$ for up to six months showed no detectable loss of reactivity when tested against the serogroup 1 rabbit antiserum, which had a titre of $1 / 16$. This titre was obtained each time regardless of length of storage up to six months. Antigen stored longer than this was not tested. Five consecutive batches of antigen showed no appreciable differences when tested against the serogroup 1 rabbit antiserum, which gave a titre of $1 / 16$ in all cases.

\section{Discussion}

The use of CIE to detect bacterial antigens in clinical material, or the antibodies they stimulate, has been applied to the diagnosis of many diseases, particularly where the causative agent is difficult to isolate. The technique is widely used for the detection of bacterial antigens in CSF or sputum and the detection of fungal and parasitic circulating precipitins. ${ }^{12}$

In this study, CIE has been adapted to the detection

Table 3 Antibody titres measured by IFA and CIE tests in sera from patients with Legionnaires' disease and rabbit antisera

\begin{tabular}{|c|c|c|c|}
\hline Patient & Days after onset & IFA titre & CIE titre with serogroup 1 antigen \\
\hline 1 & 24 & $\geqslant 512$ & 16 \\
\hline \multirow[t]{3}{*}{2} & 9 & $<32$ & Negative \\
\hline & 12 & 128 & 2 \\
\hline & 32 & 512 & 2 \\
\hline \multirow[t]{4}{*}{3} & 7 & 16 & Negative \\
\hline & 45 & 128 & 2 \\
\hline & 52 & 128 & 2 \\
\hline & 74 & 128 & 2 \\
\hline \multirow[t]{2}{*}{4} & 7 & $<16$ & Negative \\
\hline & 11 & 32 & Neat \\
\hline \multirow[t]{5}{*}{5} & 7 & 16 & Negative \\
\hline & 14 & 64 & Neat \\
\hline & 21 & 128 & 2 \\
\hline & 29 & 256 & 4 \\
\hline & 46 & 512 & 8 \\
\hline \multirow[t]{3}{*}{6} & 1 & $<16$ & Negative \\
\hline & 10 & 128 & 2 \\
\hline & 44 & $\geqslant 512$ & 8 \\
\hline 7 & 14 & 128 & 2 \\
\hline 8 & NK & 128 & 2 \\
\hline 9 & 42 & $>1024$ & 8 \\
\hline 10 & 182 & $>1024$ & 8 \\
\hline \multicolumn{4}{|l|}{ Rabbit hyperimmune serum } \\
\hline Serogroup 1 & - & 5000 (with homologous & 16 \\
\hline 2 & - & 8000 antigen) & Negative \\
\hline 3 & - & 8000 & Negative \\
\hline 4 & - & 8000 & Negative \\
\hline
\end{tabular}

NK $=$ not known 
of circulating antibody to L. pneumophila in Legionnaires' disease. To evaluate the efficiency of this technique, results of tests on 199 sera from Legionnaires' disease patients, healthy controls, and non Legionnaires' disease pneumonia patients were compared with those obtained by the IFA method, using the formalin-killed yolk sac antigen. ${ }^{6}$

In the Legionnaires' disease and normal control groups there was $100 \%$ correlation between the two methods, and in the pneumonia group, $96.7 \%$ correlation. It has been suggested that different antigens are involved in immunofluorescent and immunoprecipitating systems, ${ }^{13}$ and this may explain the $3.3 \%$ of pneumonia sera that were negative by IFA and positive by CIE. It is possible that CIE detects some cross-reacting or shared antigens with commonly encountered bacteria where IFA does not.

The criteria for diagnosis of Legionnaires' disease by IFA using the DMRQC reagents and methods are as follows: A fourfold rise in titre in paired sera to at least $1 / 64$ or a titre of at least $1 / 256$ on a single serum specimen accompanied by relevant clinical history will be accepted as diagnostic. ${ }^{10}$

It was considered desirable to evaluate whether CIE could be used as an adjunct to diagnosis where only a single serum specimen was available. Data obtained in this study suggest that CIE tests showing a change from negative to positive neat or $1 / 2$ in serial specimens, or a single specimen with a CIE titre of $1 / 4$, with relevant clinical history would be comparable to the IFA criteria. It is advised, however, that any sera showing such reactions by CIE be checked by IFA tests or sent to a CDSC reference centre for confirmation.

In this study there appear to be no cross-reacting antigens between serogroups $1,2,3$, and 4 by CIE as shown by the failure of groups 2,3 , and 4 rabbit antisera to form a precipitate with the serogroup 1 antigen. However, further investigation is needed to substantiate this fully.

Two precipitating antigens have been demonstrated by other workers, one serotype-specific and one group-specific. ${ }^{1314}$ The former appeared the stronger of the two, the latter giving only very weak lines. ${ }^{13}$ It appears, therefore, that the CIE system described here involves the serotype-specific antigen, the group-specific antigen being undetectable, although human sera with IFA titres to other serogroups were not tested in this study.

Precipitins can be demonstrated as early as 10 days after onset, which compares well with IFA (Table 3), although low titre reactions obtained this early tend to be weak, and some experience may be needed in reading the slides. Purification of the crude antigen described here was not attempted as results obtained indicated that this was unnecessary

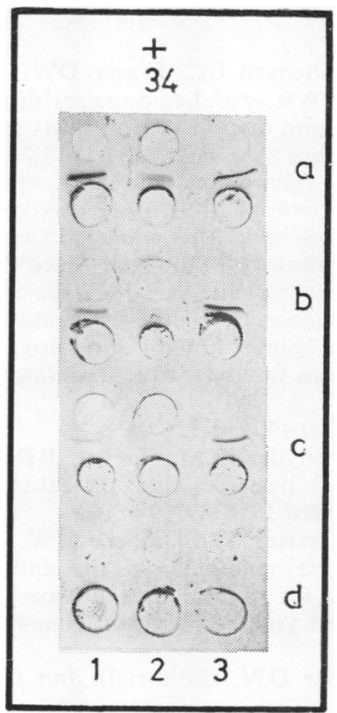

Demonstration of precipitating antibodies in

Legionnaires' disease by CIE. Slide stained in naphthalene black. Horizontal rows $a, b, c$, and d are doubling dilutions of sera 1,2 , and 3 , showing positive reactions in rows $a, b$, and $c$, but no reactions in row $d$. Strong positives can be seen with sera 1 and 3 , whereas serum 2 gives noticeably weaker reactions.

at this time (Figure).

The antigen appears to be relatively stable at $4^{\circ} \mathrm{C}$, and different batches show acceptable reproducibility.

It is intended that this system be extended to other serogroups of $L$. pneumophila, and attempts to detect soluble antigens of $L$. pneumophila in clinical specimens by CIE are at present in progress.

I am greatly indebted to Dr AG Taylor, Division of Microbiological Reagents and Quality Control, Colindale. London, for supplying the heat-killed $L$. pneumophila cells, the sera from confirmed Legionnaires' disease and non-Legionnaires' disease patients, and for providing the IFA titres for these sera. Without Dr Taylor's generous help and advice this work would not have been possible.

I also thank Dr E Nnochiri, consultant microbiologist, Stafford and Burton on Trent; Mr IL McCartney, chief MLSO, Microbiology Laboratory, Stafford; PHL Carlisle; the Microbiology Department, Dudley Guest Hospital and the Pathology Laboratory, Stafford, for use of equipment and technical assistance; Mrs D Johnson and Mrs L Holliday for typing the manuscript; and the staff of the Microbiology Laboratory, Stafford, for encouragement when needed. 


\section{References}

${ }^{1}$ McDade JE, Shepard CC, Fraser DW, Tsai TR, Redus MA,Dowdle WR, et al. Legionnaires' disease: Isolation of a bacterium and demonstration of its role in other respiratory disease. $N$ Engl J Med 1977;297:1197-203.

2 Baine WB. Legionnaires' disease: epidemiology and clinical characteristics. In: Legionnaires. The Disease, The Bacterium and Methodology. Centre for Disease Control Laboratory Manual. Revised Oct 1978, 23-8.

${ }^{3}$ Brenner DJ, Steigerwalt AG, McDade JE. Classification of the Legionnaires' disease bacterium: Legionella pneumophila, genus novum spp. nova of the Family Legionellaceae familia nova. Ann Intern Med 1979;90: 656-8.

${ }^{4}$ Editorial. Lancet 1977;ii:1265-6.

${ }^{5}$ Kirkby BD, Snyder KM, Meyer RD, Finegold SM. Legionnaries' disease: clinical features of 24 cases. Ann Intern Med 1978;89:297-309.

${ }^{6}$ Taylor AG, Harrison TG, Dighero MW, Bradstreet CMP. False positive reactions in the indirect fluorescent antibody test for Legionnaires' disease eliminated by use of formolised yolk-sac antigen. Ann Intern Med 1979; 90:686-9.

7 Tsai TF, Fraser DW. (Editorial) Ann Intern Med 1978; 89:413.
${ }^{8}$ Editorial. Br Med J 1978;ii:1319-20.

${ }^{9}$ Fallon RJ, Abraham WH. Scottish experience with the serologic diagnosis of Legionnaires' disease. Ann Intern Med 1979;90:684-6.

${ }^{10}$ Taylor AG. Personal communication, 1979

${ }^{11}$ Greaves PG, Sharp G, Macrae AD. Isolation of Legionella pneumophila. Lancet 1979;i:551-2.

12 Corkill JE. Counterimmunoelectrophoresis. Current Topics in Medical Laboratory Sciences, 1977, No. 2.

${ }^{13}$ McKinney RM, Thacker L, Harris PP, Lewallen KR, Hebert GA, Edelstein PH, Thomason BM. Four serogroups of Legionnaires' disease bacteria defined by direct immunofluorescence. Ann Intern Med 1979;90: $621-4$

${ }^{14}$ Wong KH, Schalla WO, Arko RJ, Bullard JC, Feeley JC. Immunochemical, serologic and immunologic properties of major antigens isolated from Legionnaires" disease bacterium. Ann Intern Med 1979;90:634-8.

Requests for reprints to: Malcolm G Holliday, Microbiology Department, St George's Hospital, Stafford ST163AG. 